\title{
Corf-940241--1
}

UCRLJJC-115463

PREPRINT

\section{Improved Ground-Penetrating Radar, Bridge Decks}

\author{
John P. Warhus \\ Jeff E. Mast \\ Erik M. Johansson \\ Scott D. Nelson
}

This paper was prepared for submittal to the:

Structural Materials Technology -

Non-Destructive Technology Conference

Atlantic City, NJ

February 23-25, 1994

November 29, 1993

This is a preprint of a paper intended for publication in a journal or proceedinga. Since changes may be made before pablication, this preprint is made available with the understanding that it will not be cited or reproduced without the permission of the author.

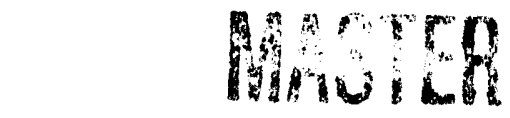




\section{DISCLAIMER}

This document was prepared as an accounit of work sponsored by an agency of the United States Government. Neither the United States Government nor the University of California nor any of their employees, makes any warranty, express or implied, or assumes any legal liability or responsibility for the accuracy, completeness, or usefulness of any infurmation, apparatus, product, or process disclosed, or represents that its use would not infringe privately owned rights. Reference herein to any specific commercial products, process, or service by trade name, trademark, manufacturer, or otherwise, does not necessarily constitute or imply its endorsement, recommendation, or favoring by the United States Covernment or the University of California. The views and opinions of authors expressed herein do not necessarily state or reflect those of the United States Government or the University of California, and shall not be used for advertising or product endorsement purposes. 
Title:

IMPROVED GROUND-PENETRATING RADAR, BRIDGE DECKS

Authors:

John P. Warhus,

Jeffery E. Mast,

Erik M. Johansson,

Scott D. Nelson 


\begin{abstract}
Inspection of high-value structures, like bridges and buildings, using Ground Penetrating Radar (GPR) is an application of a technology that is growing in importance. In a typical inspection application, inspectors use GPR to locate structural components, like embedded reinforcing bars, to avoid weakening the structure while collecting core samples for detailed inspection. Advanced GPR, integrated with imaging technologies for use as an NDE tool, can provide the capability to quickly locate and characterize construction flaws and wear- or age-induced damage in these structures without resorting to destructive methods. In this paper, we discuss an important inspection application, namely, concrete bridge deck inspection. We describe an advanced bridge deck inspection system concept (Ground Penetrating Imaging Radar, GPIR) and present results from experiments designed to simulate the concept.
\end{abstract}

\title{
BACKGROUND
}

An advanced GPR-based inspection system has the near-term potential of addressing critical national and international needs for reliable, cost effective NDE of bridges and other reinforced concrete structures. There are more than 578,000 highway bridges in the US and more than $\mathbf{4 0}$ percent of them are structurally deficient or functionally obsolete [1]. Thiese conditions limit bridge utility, and, if they are not properly monitored and maintained, can pose a threat to the bridge users safety.

The bridge deck and its wearing surface are the most vulnerable parts of a bridge to damage from routine service, and they are particularly well suited for inspection using a vehicle mounted inspection system. The deck has a shorter average service life (35 years) than the bridge itself ( 68 years). The wearing surface of the deck, which serves as the driving surface and protects the deck beneath it, is usually designed to be replaced many times over the life of the bridge. Concrete slabs with concrete or asphalt wearing surfaces are the most widely used decks in all types of bridges [2].

J.P. Warhus, J.E. Mast, E.M. Johansson, S.D. Nelson, University of California, Lawrence Livermore National Laboratory, Electronics Engineering Department, P.O. Box 808, Livermure, CA 94551 . Work performed under the auspices of the U.S. Department of Energy by Lawrence Livermore National Laboratory under Contract no. W-7405-Eng-48. 
In an advanced bridge deck inspection system, like the one described below and in [3, 4, and 5], a mobile GPIR gathers data for high-resolution image reconstruction of embedded defects and features. High-quality images allow visualization of internal structure, permitting evaluation of the condition with data that usually are obtainable only with destructive methods. Performance enhancements are achieved by the application of advanced hardware and software. Traffic-lane-wide coverage is enabled by the use of new transmitters, antennas, and large-aperture receiving arrays. High-speed data acquisition and accompanying inspection vehicle speed are feasible with multiple receiver channels using state-of-the-art data transmission and storage equipment. Down range resolution is improved by increased transmitter pulse bandwidth and enhanced antenna performance. Cross-range capabilities are exploited by applying synthetic aperture radar data processing techniques to produce three-dimensional spatial images.

\section{ADVANCED GPIR CONCEPT}

The system concept for an advanced GPIR system is illustrated in Figure 1. An inspection vehicle equipped with a transmitting antenna and a linear array of receivers travels over the bridge deck, sweeping out a traffic-lane-wide synthetic aperture. Data recorded from the receivers are transferred via multiple data streams to a mass data storage subsystem, from which they can be accessed for image reconstruction. Appropriate transmitted power and receiver sensitivity levels permit data acquisition to depths of $0.3 \mathrm{~m}$ in the deck. High-speed image-processing computers, in centrally-located processing centers, reconstruct images of the bridge deck for evaluation by a bridge inspector. Highresolution, three-dimensional images for a typical bridge are reconstructed in less than one hour. Images have calculated resolution limits of $15 \mathrm{~mm}$ in depth and $50 \mathrm{~mm}$ in azimuth.

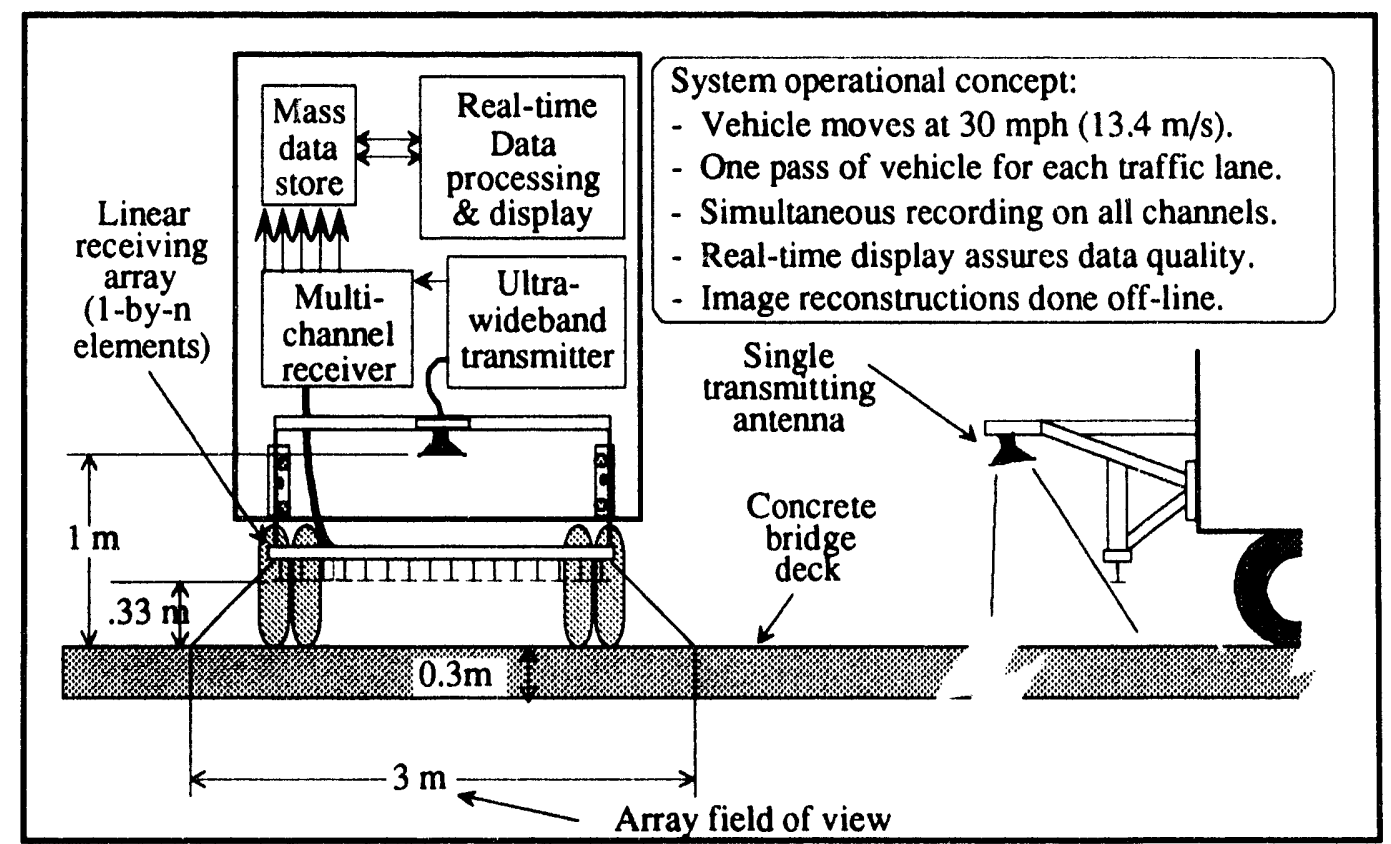

Figure 1. Advanced GPIR Bridge Deck Inspection System Concept 


\section{CONCEPT DEVELOPMENT}

Our approach to development of system and subsystem concepts for an advanced bridge inspection system has involved modeling, experiments, design and test of advanced GPR components, and development of unique image reconstruction techniques. This paper describes experimental results and image reconstructions. An overview of the development program including modeling, experimental and imaging efforts can be found in $[3,4$, and 5$]$.

\section{RECENT RESULTS}

In recent testing, we collected data and reconstructed images of features embedded within a concrete test bed. In these experiments, we collected data using monostatic antennas driven by a low-power impulse generator ( $\sim$ watt, peak), limiting penetration depth to 150 to $170 \mathrm{~mm}$. Data were acquired with the receiving antenna configured to receive the cross-polarized returns scattered from targets and clutter in the illuminated volume and recorded using a sampling oscilloscope. The antennas were mounted $75 \mathrm{~mm}$ above the concrete surface, and moved over of the test bed while collecting data over a square sampling grid at $12.7 \mathrm{~mm}$ spatial intervals. The test bed is a concrete slab $(\sim 2 \mathrm{~m}$-by$2 \mathrm{~m}$-by- $0.3 \mathrm{~m}$ thick) containing fixed and removable steel reinforcing bars (rebars), and other objects which simulate layer de-bonding and spalling defects. Simulated defects are constructed from Teflon ${ }^{\mathrm{TM}}$ with a dielectric constant of $\sim 2$, very close to air.

\section{IMAGING METHOD}

The imaging algorithm used to form the image in figure 2 is based on a multi-frequency diffraction tomography method which takes the acquired time-domain data and generates a spatial image of the interior structure. The unprocessed data are a collection of time delayed reflections of the GPR impulse from subsurface interfaces. Those reflections are mapped into a high resolution spatial image of the scatterirg interfaces. This procedure provides an increased signal to noise ratio, improved cross-range resolution, and improved interpretability in comparison to conventional data analysis and display techniques.

Prior to image formation, the data are processed using several standard techniques to improve data quality. Preprocessing steps include background subtraction to remove the front surface reflection, and pulse deconvolution to improve signal-to-noise ratio and temporal resolution. The resolution attained in the reconstructed image is dependent upon several factors including frequency bandwidth, antenna beamwidth, distance from the antenna and electrical properties of the medium. The data acquisition for this particular experiment allowed a resolution cell size of about $50 \mathrm{~mm}$.

\section{EXPERIMENTAL RESULTS}

Results from imaging the experimental data are shown in Figure 2 as a 3-dimensional (3-

D) visualization of the embedded structure. Three-dimensional rendering gives an overall perspective of object orientation and shape within the volume. Four reinforcing bars (rebars) are clearly visible in the rendering. The tilted rebar is visible only at shallower depths due to shadowing by the rebars crossing over it and the limited signal penetration depth. One of the simulated spall defects is visible in the upper corner of the rendering. 


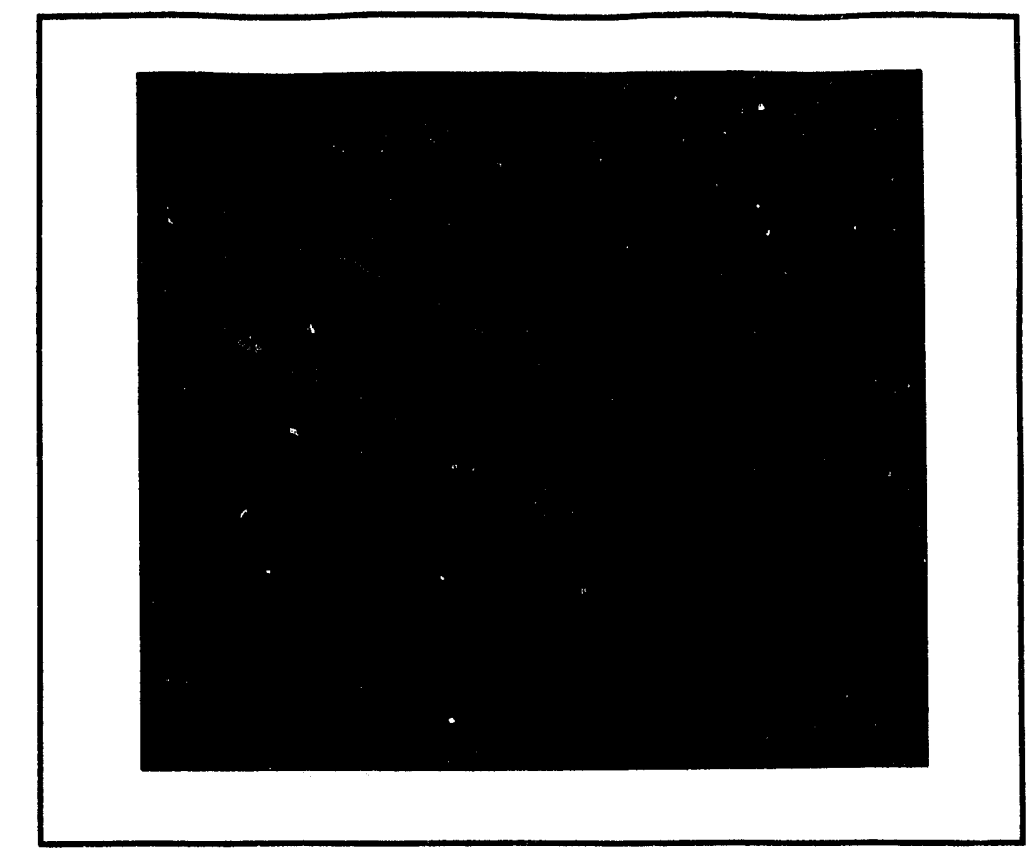

Figure 2. Three Dimensional Rendered Image of Interior of Test Bed

The color-map and scaling used in the rendering do not permit visualization of the simulated defects; to visualize those objects, we use planar slices. Figures 3 and 4 are planar slices of the portion of test bed containing the simulated spall and de-bonding defects. In figure 3, a large (75 mm radius half-cylinder) spall defect is visible in the upper-left corner; a smaller ( $50 \mathrm{~mm}$ radius) spall simulation is barely visible just to the right of it. In figure 4, the simulated de-bonding defects $(250 \mathrm{~mm}$ and $200 \mathrm{~mm}$ square plates) are discernible; they appear at the bottom of the image, to the left and right (respectively) of the rebar running vertically through the image. The bases of the simulated defects are located at a depth of $150 \mathrm{~mm}$ in the test bed concrete.

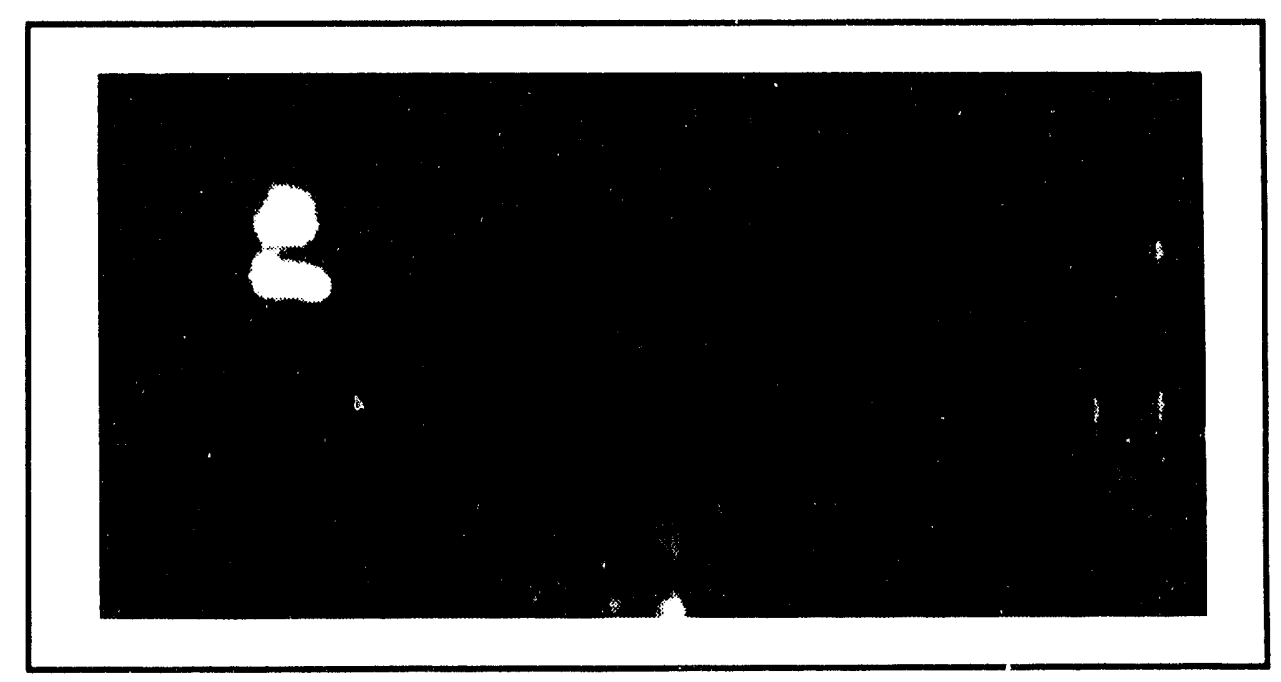

Figure 3. Planar Slice of 3-D Image of Test Bed at $100 \mathrm{~mm}$ Depth 


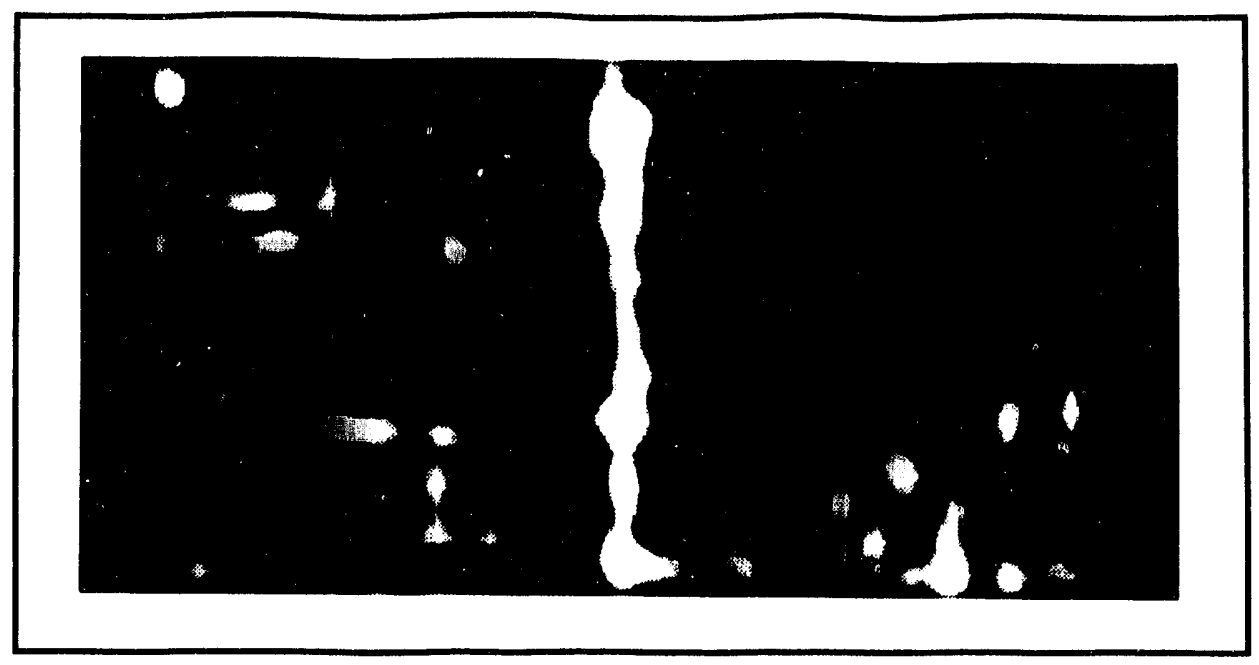

Figure 4. Planar Slice of 3-D Image of Test Bed at $140 \mathrm{~mm}$ Depth

\section{CONCLUSIONS}

GPR combined with unique image reconstruction algorithms has the potential for providing rapid, cost-effective means for large-area inspection of bridge decks. A basic inspection system design concept was described which is being developed at LLNL and used to guide development of GPIR hardware and imaging algorithms. A laboratory testing capability has been established to evaluate GPIR components, subsystems, and systems. Recent test and image processing results have produced high quality reconstructed images of subsurface test objects. The results show that the inspection concept is feasible.

\section{REFERENCES}

1. "Our Nation's Highways: Selected Facts and Figures"; US Department of Transportation, Federal Highway Administration; Publ. No. FHWA-PL-90-024.

2. Jones and B.R. Ellingwood, "NDE of Concrete Bridges: Opportunities and Research Needs," Federal Highway Administration Conf. on NDE for Bridges, Arlington, VA, (August 25-27, 1992).

3. J.P. Warhus, J.M. Hernandez, S.D. Nelson, E.M. Johansson, and H. Lee, "Ground Penetrating, Imaging Radar for Bridge Inspection," Engineering Research, Development, and Technology Thrust Area Report FY-92, Lawrence Livermore National Laboratory, Livermore, CA UCRL 53868-92, (March 1993).

4. J.P. Warhus, J.E. Mast, S.D. Nelson, and E.M. Johansson, Ground-Penetrating Imaging Radar Development for Bridge Inspection, Lawrence Livermore National Laboratory, Livermore, CA UCRL-ID-1 13954 (May 1993).

5. J.P. Warhus, J.E. Mast, S.D. Nelson, E.M. Johansson, H. Lee, "Advanced GroundPenetrating, Imaging Radar for Bridge Inspection," in Review of Progress in Quantitative Nondestructi'e Evaluation, Vol. 13, May 1994, (Plenum, New York, 1994). 

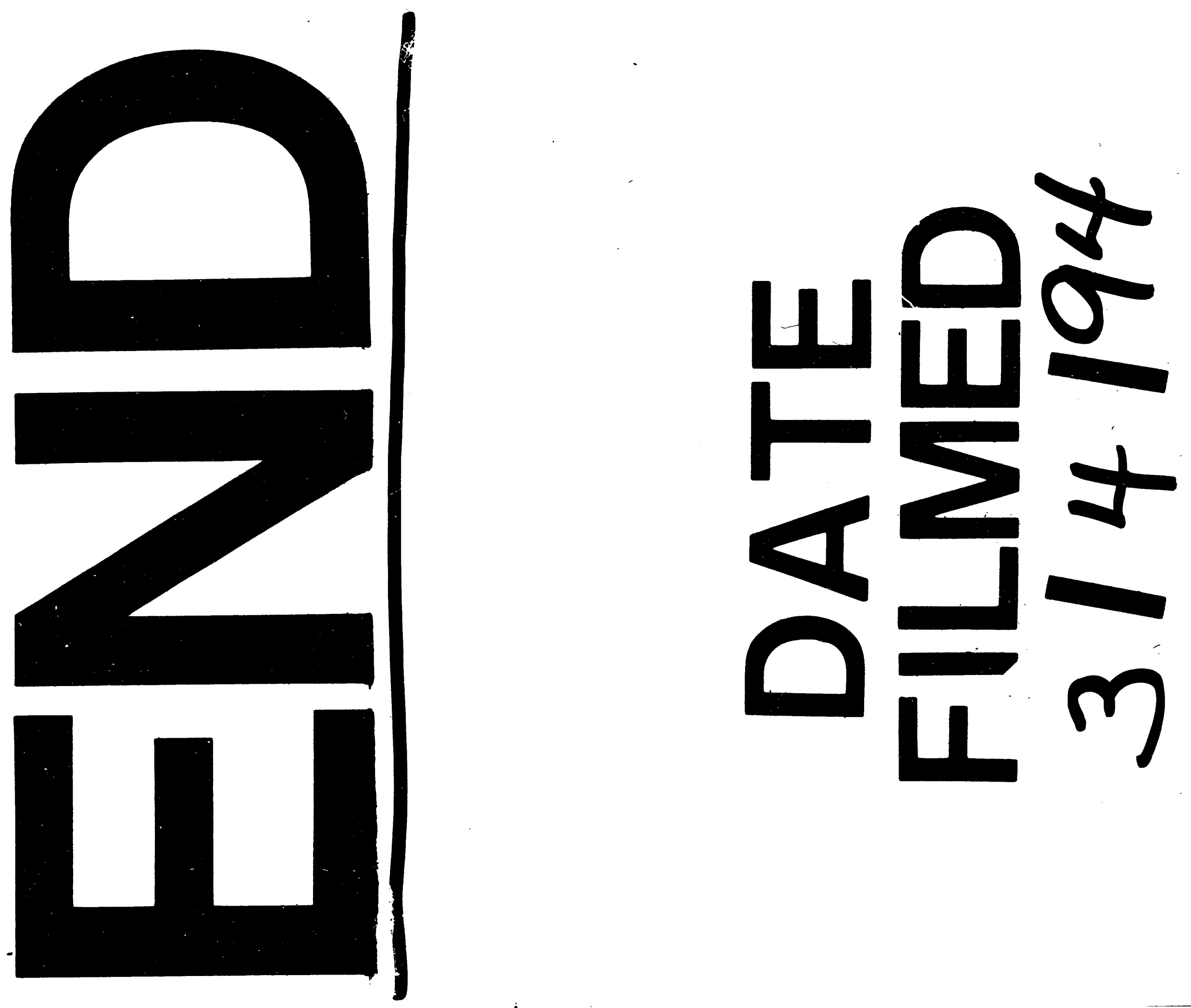
